Research Article

\title{
Earthquake Response Control of Double-Layer Truss Walls by means of Innovative Fuse Connections
}

\author{
Koichiro Ishikawa \\ University of Fukui, Fukui-shi, Japan \\ Correspondence should be addressed to Koichiro Ishikawa; ishikawa@u-fukui.ac.jp
}

Received 8 May 2018; Accepted 8 July 2018; Published 15 August 2018

Academic Editor: David M. Boyajian

Copyright ( 92018 Koichiro Ishikawa. This is an open access article distributed under the Creative Commons Attribution License, which permits unrestricted use, distribution, and reproduction in any medium, provided the original work is properly cited.

\begin{abstract}
This study deals with partial cylindrical truss walls equipped with damper connections due to horizontal earthquake motions. The damper connection consists of an aluminum ball joint, an aluminum hub, and a steel bolt. A ductile elongation of the steel bolt due to a tensile stress is expected by avoiding the brittle collapse. The study proposes a fuse-type connection by means of yield of the steel bolt due to tension stress realized by the ductile failure collapse mechanism of the wall-type spatial structure. The proposed truss wall with the fuse-type connection can realize a deformation of nodes within the restriction for avoiding a nonstructural member damage. It is confirmed in the dynamic elastoplastic analysis that the control of the dynamic collapse mechanism such as the steel bolt elongation can avoid a brittle collapse mechanism such as a chain of member buckling. The evaluation method is also proposed by means of the limit displacement considering a ductility factor of the steel bolt within 2.0.
\end{abstract}

\section{Introduction}

This study deals with the dynamic elastoplastic analysis considering a member buckling, and the fuse-type connection consists of an aluminum ball joint, an aluminum hub, and a steel bolt. A ductile elongation of the steel bolt due to a tensile stress is expected by avoiding the brittle collapse in our previous paper [1-3]. The study proposes a fuse-type connection by means of yield of the steel bolt due to tension stress realized by the ductile failure collapse mechanism of the wall-type spatial structure.

The seismic response characteristics of spatial structures such as roof and wall types depend on their form and support conditions, and several reviews $[4,5]$ and guidelines [6-13] quoting many studies have been published depending on the performance of building structures. Several performance prediction methods have been developed for this purpose; however, the earthquake resistance capacity of spatial structures requires the variation of the form and the support condition, and it is very difficult to apply them to wall-type spatial structures. For the performance design, several prediction methods such as a pushover analysis and an adaptive capacity spectrum method have been developed for structures such as buildings and bridges [14-18].
The control of the dynamic collapse mechanism is also proposed to improve the earthquake resistance capacity by a damper connection such as the steel bolt elongation.

Effect of the member buckling and yield elongation of the steel bolt on the seismic response out of the plane is shown in comparison with the response of the wall structure subjected to the horizontal earthquake motions. The earthquake evaluation method is also proposed considering the dynamic collapse mechanism. A validity of the proposed method is shown by means of the accuracy between the analysis and the estimation.

\section{Examples of Aluminum Truss Structures}

Since earthquake resistance standards in Japan were improved, buildings which were designed on the basis of old seismic standards before 1981 need to be reinforced quickly on the basis of the exiting new ones.

The aluminum braces are useful for seismic retrofitting of existing buildings because they achieve good workability in the erection site and reduce the seismic loading and additional loads on the foundations due to their lightweight and aluminum alloy members owing to their long-term corrosion resistance.

Figure 1 shows double-layer latticed walls and roofs made of an aluminum alloy truss system, and the walls 


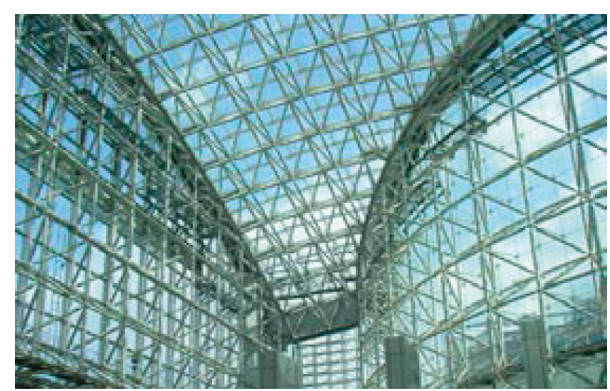

(a)

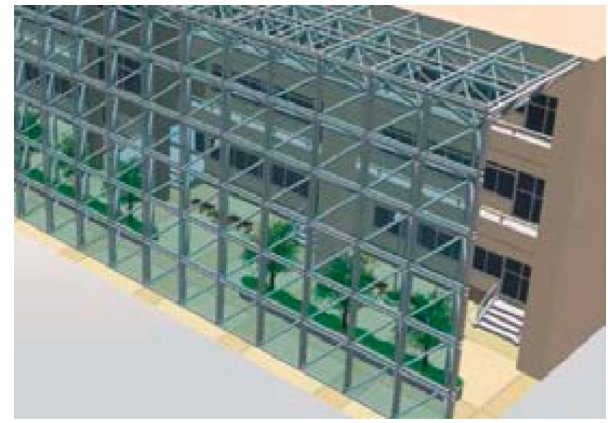

(c)

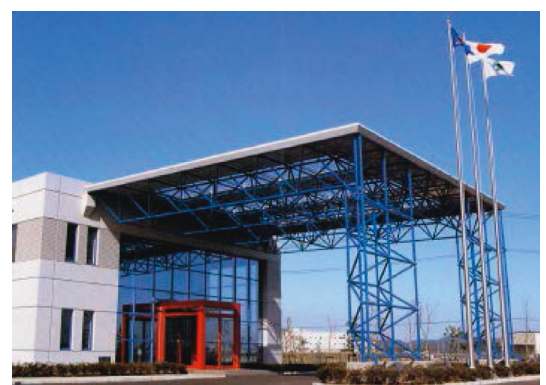

(b)

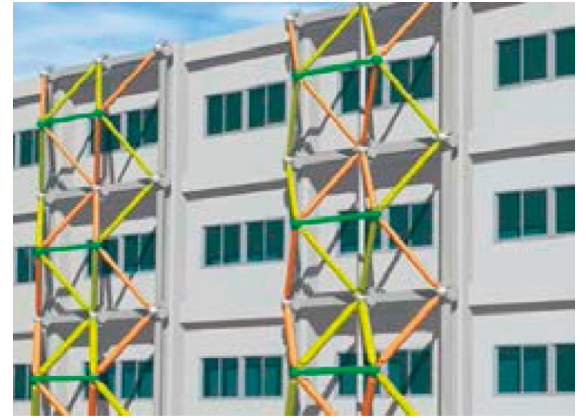

(d)

FIgURe 1: Aluminum truss walls and retrofit.

resist in-plane shearing load in an earthquake. Figures 1(a) and 1(b) show the entrance canopy of the office and the atrium at the entrance of the railroad station, and they are L-shaped application of an aluminum truss wall. The truss walls achieve structural rigidity and strength on seismic loading, and the slender members with cladding prevent daylight. Figures 1(c) and 1(d) are CG images of seismic retrofit of RC school buildings using the aluminum truss walls.

\section{Connection Design of an Aluminum Truss Wall}

We propose two types of connection systems: an aluminum ball-jointed truss wall and aluminum pin-connected braces. As described in more detail below, both systems have improved in their plastic deformability to resist excessive seismic loads. In our previous paper [1], the brittle collapse mechanism of the truss wall structure to resist lateral loads has been investigated to evaluate the earthquake resistance capacity.

Figure 2 illustrates the aluminum alloy ball-jointed truss connection used to retrofit; this nodal connection consists of aluminum parts and a steel bolt. All aluminum parts are extruded, and in heat-treated aluminum alloy 6061-T6, the end plug is welded at its edge to the strut by using a friction welding method. Friction welding, which is one of the various welding processes, is known for high joint efficiency and high reliability in comparison with MIG or TIG welding. The collar transfers the compression stress, and the steel bolt

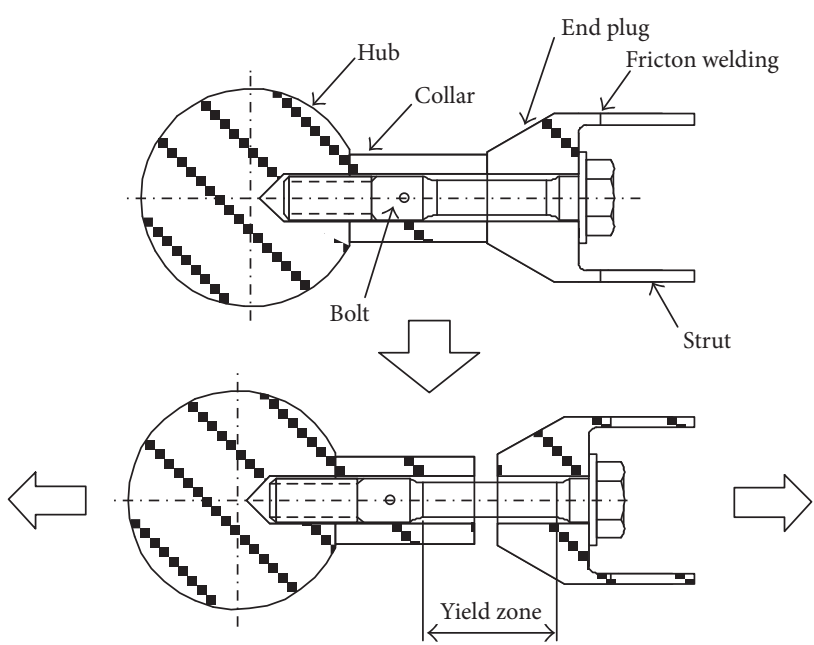

FIGURE 2: Yielding bolt mechanism.

transfers the tension stress. The bolt is made of high-strength steel; the figure of the bolt is slimmed in the axle of the bolt as shown in Figure 2.

The connection of the truss wall is designed by means of the condition such as $N_{\mathrm{cr}}>{ }_{\mathrm{B}} \mathrm{Nu}$, where $N_{\mathrm{cr}}$ is a member buckling or an ultimate strength of the welded joint and ${ }_{B} \mathrm{Nu}$ is an ultimate strength of the bolt. The bolts are able to extend by excessive tensile loading in a major earthquake; therefore, the truss wall structure achieves a good hysteretic curve as described in Figure 3. In our previous paper [2], it is investigated that the fuse-type connection realizes the tension yield of the steel bolt before the member buckling occurs. 


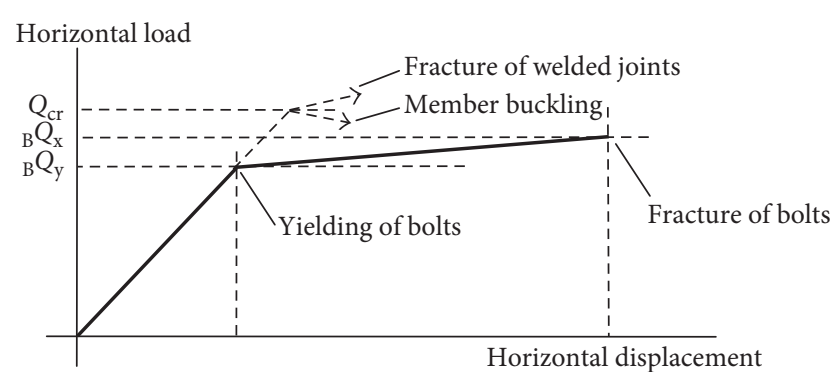

FIgURE 3: Hysteretic curve of the truss wall used to retrofit.

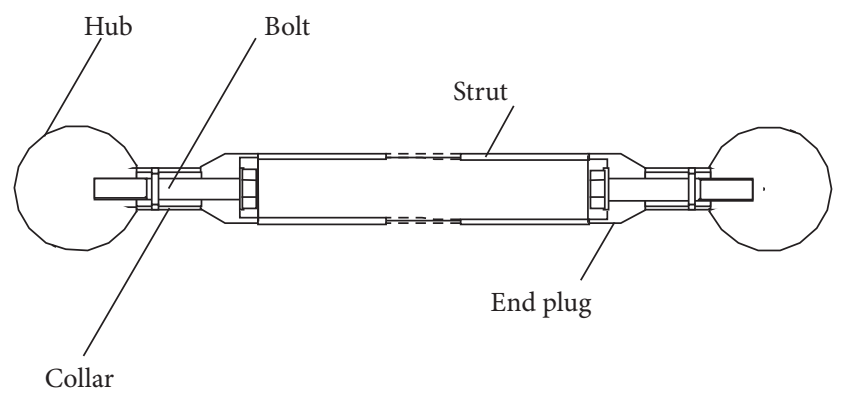

Figure 4: Truss system.
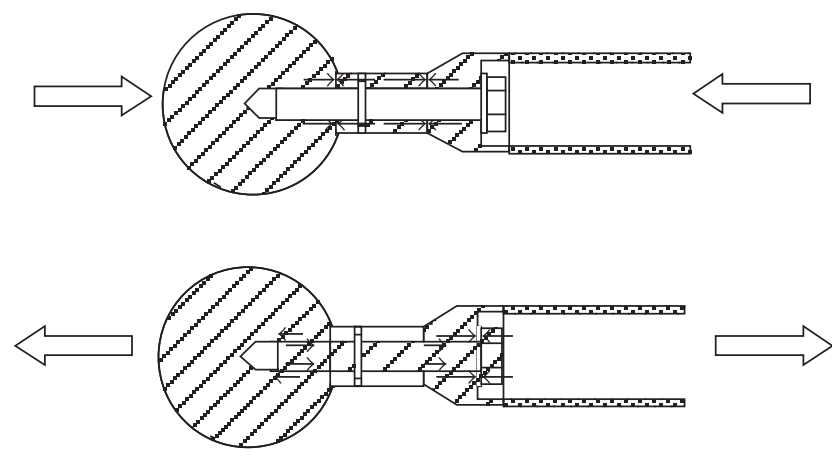

Figure 5: Mechanism of stress transfer.

\section{Truss Members including Joints and Modeling}

The fuse connection consists of two hubs, two collars, two bolts, and a strut, as shown in Figure 4. The steel bolt resists against the tension axial stress, and the collar resists against the compression axial stress, as far as the resistance mechanism of the axial stress between the hub and strut is concerned. Figures 5-7 show the numerical analysis model in this study.

\section{Hysteresis Models of the Truss Member}

The present analysis adopts an assumption that struts buckle due to compression and yield under tension. Figure 8 shows the hysteresis curves used for the slenderness ratio of a member. The maximum compressive stress $\sigma_{\mathrm{cr}}$ is determined using (1) which considers member crookedness and the residual stresses existing in the strut. Figure 9 shows the hysteresis curves of the steel bolt which yields under tension and slips under compression. The hub resists against the compression instead of the yielding bolt. The yield stress $\sigma_{\mathrm{y}}$ and Young's modulus $E$ are taken to be $210 \mathrm{MPa}$ and $70 \mathrm{GPa}$, respectively. The maximum compressive stress $\sigma_{\mathrm{cr}}$ is calculated by (1), and the maximum tension stress of the weld fracture is taken to be $0.71 \sigma_{\mathrm{y}}$ due to a tension axial stress. The initial tension stress is not introduced in the steel bolt:

$$
\begin{aligned}
\frac{\lambda}{\Lambda} \leq 1.0: \sigma_{\mathrm{cr}} & =\frac{F}{\left\{1-0.5(\lambda / \Lambda)^{2}\right\}} \\
\frac{\lambda}{\Lambda}>1.0: \sigma_{\mathrm{cr}} & =\frac{F}{\left\{2(\lambda / \Lambda)^{2}\right\}} \\
\Lambda & =\sqrt{\frac{\pi^{2} E}{0.5 F}}=\frac{37.17}{\sqrt{F}}=81.1 .
\end{aligned}
$$

\section{Time-History Analysis of the Truss Wall}

Geometric and material nonlinearity is considered in the time-history analysis of the truss walls subjected to the horizontal earthquake motion of El Centro NS (PGA: $\left.5.61 \mathrm{~m} / \mathrm{sec}^{2}\right)$. The Rayleigh damping matrix is used in this analysis. The damping factor $h=0.02$ is used for first and second vibration modes in the damping matrix. The numerical integration method uses the Newmark method. $\beta=1 / 4$ is used in this study because $\beta=1 / 4$ will be unconditionally stable for the seismic response analysis.

6.1. Analysis Model of the Double-Layer Partial Cylindrical Truss Wall. The truss wall has a configuration as shown in Figure 10. The length is $14 \mathrm{~m}$ with 7 grids, and the height is $7.2 \mathrm{~m}$ with 4 grids. The bottom nodes are constrained for all directions. The top nodes are free for the horizontal plane ( $X$ direction). They are restrained for the vertical direction ( $Y$ direction) and out of the plane $(Z$ direction).

An aluminum alloy A6061-T6 is used in the strut, and a high tensile strength steel SCM435 with the yield strength of $649 \mathrm{~N} / \mathrm{mm}^{2}$ is used in the connection steel bolt. A truss model is used in the analysis. The model is a lightweight structure made of an aluminum alloy. The structure can bear the dead load, which is confirmed as the static design.

Table 1 shows the member length $L(\mathrm{~mm})$, the slenderness ratio $\lambda$, the cross-sectional secondary radius $i(\mathrm{~mm})$, and the sectional area $A\left(\mathrm{~mm}^{2}\right)$. The member is determined by the earthquake-proof design using the base shear coefficient of 1.0. And the strength of pullout of the bolt such as the yield axial force is also shown in Table 1.

6.2. Vibration Characteristics and Seismic Responses of the Truss Wall. The natural period and the vibration mode of 


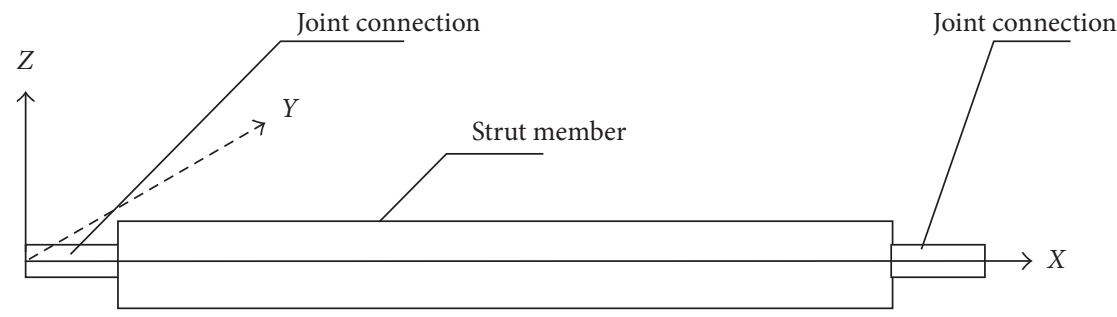

Figure 6: Components of the member.

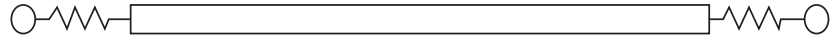

Figure 7: Truss model of each element for analysis.

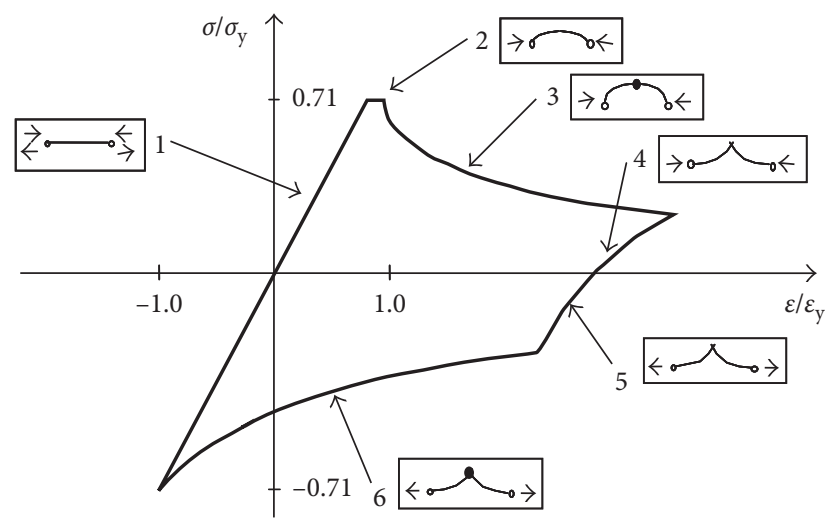

Figure 8: Hysteresis model of the aluminum strut.

the two walls with the $1 \mathrm{~m}$ and $0.4 \mathrm{~m}$ wall depths are obtained by means of the eigenvalue analysis, respectively. The first and third natural periods $T_{1}$ and $T_{3}$ are shown in Figure 11. The corresponding vibration modes are also shown in Figure 11, respectively. It is seen that the shear deformation mode of a wall appears in the first vibration mode of the two walls and the third mode of the wall with the $1 \mathrm{~m}$ depth. The out-of-plane shape in the third mode of the wall with the $0.4 \mathrm{~m}$ depth also appears due to the lower bending rigidity than in the wall with the $1 \mathrm{~m}$ depth. The study focuses on the out-of-plane deformation of the thin depth wall subjected to earthquake motions.

6.3. Dynamic Response Behavior of the Truss Walls Subjected to Earthquake Motions. In the present study, the earthquake resistance capacity of the dome is evaluated by investigating the maximum horizontal displacement $\delta_{\text {max }}$ at the top of the wall subjected to horizontal earthquake motions with the peak ground acceleration (PGA) multiplied by the PGA amplification factor $\lambda_{\mathrm{E}}$. The damage limit artificial earthquake motion with a phase characteristic of the El Centro NS wave is used in the seismic response analysis. The PGA is taken to be $1.12 \mathrm{~m} / \mathrm{sec}^{2}$. The relationship between $\lambda_{\mathrm{E}}$ and $\delta_{\max }$ of the two walls with different wall depths is shown in Figures 12 and 13. The location of the steel bolt yield is shown in Figure 14 at the beginning of the bolt yield and the member buckling, respectively. It is seen in the results that the bolt yield precedes the member buckling and the linear relationship between $\lambda_{\mathrm{E}}$ and $\delta_{\max }$ is kept within the plastic region from the beginning of the bolt yield to the beginning of the member buckling. This means that the response control can be feasible by means of the fuse-type connection such as the steel bolt yielding elongation.

The time-history energy response of the restoring force of the member and the damping of the structure to the in-plane $(X)$ and out-of-plane $(Z)$ directions is shown in Figures 15 and 16, respectively. It is seen in the wall with depths that the structural damping almost absorbs the input energy due to the seismic response just before the member buckling occurs. The member buckling induces the absorbed energy in the case of the wall with $1 \mathrm{~m}$ depth subjected to earthquake motions with $\lambda_{\mathrm{E}}=9.4$. The out-of-plane also consumes energy greater due to member buckling as seen in Table 2. On the contrary, a sudden dynamic collapse of the wall with the $0.4 \mathrm{~m}$ depth occurs just after the member buckling because of the bending rigidity out of the plane with the less wall depth.

The maximum strains of the steel connection bolt in both depths are 2 times less than the first yield strain as shown in Figure 17. It is confirmed in the study that all members in both walls are also 2 times less than the first yield strain.

\section{Evaluation Method of the Response Estimation by means of the Limit Displacement}

The comparison between the PGA amplification factor $\lambda_{\mathrm{E}}$ of the input earthquake motion and the maximum displacement $\delta_{\max }$ to the horizontal in-plane $(X)$ direction at the top of the wall with the $1 \mathrm{~m}$ and $0.4 \mathrm{~m}$ wall depths is shown in Figure 18 by means of the dynamic analysis. And the proposed estimation method uses the limit displacement. The limit displacement $\delta_{\mathrm{ud}}$ is defined in the study as $1.2 \delta_{\mathrm{y} 1}$ in the red line in Figure 18. The structural yield displacement $\delta_{\mathrm{y} 1}$ is the horizontal in-plane displacement $\delta$ at the top of the wall just on the first occurrence of the steel bolt yield. It is also noticed that a ductility factor of the steel bolt is taken to be within 2.0 at the limit displacement $\delta_{\mathrm{ud}}$. This is the reason that the limit displacement $\delta_{\mathrm{ud}}$ is taken to be $1.2 \delta_{\mathrm{y} 1}$. The structural buckling displacement 


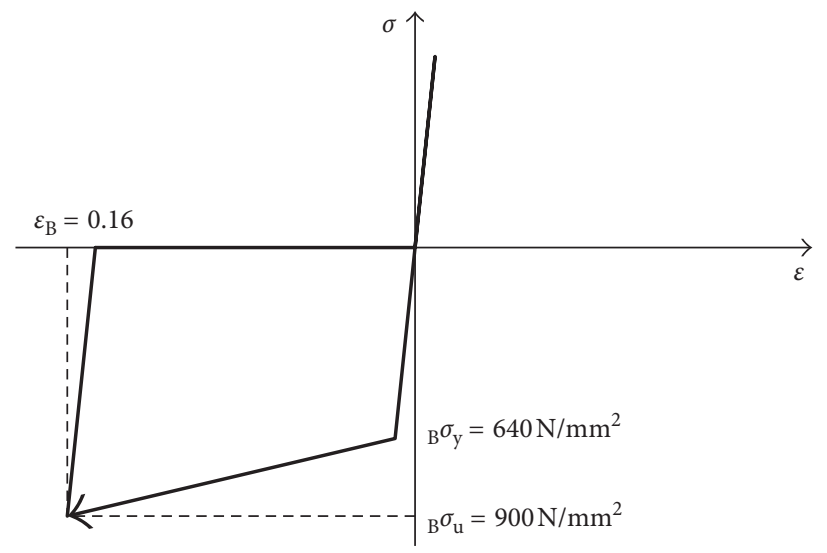

Figure 9: Hysteresis model of the steel bolt.

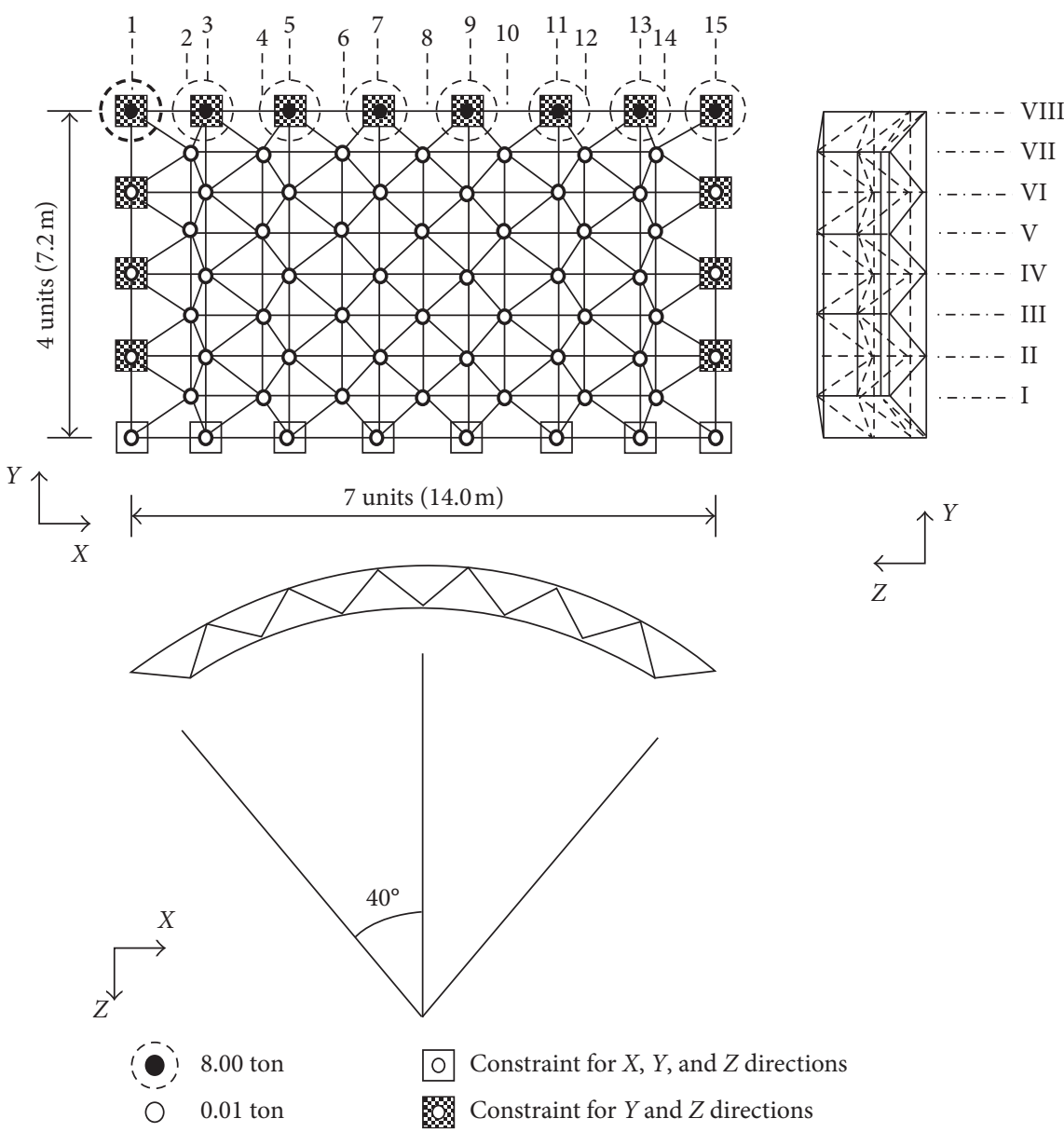

FIGURE 10: Analysis model of the double-layer partial cylindrical truss wall.

$\delta_{\mathrm{y} 2}$ is the horizontal in-plane displacement $\delta$ at the top of the wall just on the first occurrence of the strut member buckling.

The evaluation method of the response estimation by means of the limit displacement is the first to calculate the $\delta_{\max }$ using the linear relationship between $\lambda_{\mathrm{E}}$ and $\delta_{\max }$. It can be evaluated for engineers that the dynamic collapse occurs in the case of $\delta_{\max }$ larger than $\delta_{\mathrm{ud}}$. The estimation value $\lambda_{\mathrm{EU}}$ is practically calculated by the proposed method using the response analysis. The proposed method can be applied to the wall with an aspect ratio of the shear-dominant deformation type.

\section{Conclusions}

This study deals with the partial cylindrical truss wall with the damper joint connection due to horizontal earthquake motions. It is confirmed in the dynamic elastoplastic analysis 
TABLE 1: Member characteristics of the truss wall.

\begin{tabular}{|c|c|c|c|c|c|}
\hline & \multicolumn{5}{|c|}{ Wall depth: $1.0 \mathrm{~m}$} \\
\hline & Strut $(\mathrm{mm})$ & $\begin{array}{c}\text { Sectional } \\
\text { area }\left(\mathrm{mm}^{2}\right)\end{array}$ & $\begin{array}{l}\text { Cross-sectional } \\
\text { secondary } \\
\text { radius }(\mathrm{mm})\end{array}$ & $\begin{array}{c}\text { Member } \\
\text { length }(\mathrm{mm})\end{array}$ & $\begin{array}{c}\text { Slenderness } \\
\text { ratio/limit } \\
\text { slenderness ratio }\end{array}$ \\
\hline Chord member of $X$ direction & $\phi 180 \times \mathrm{t} 21$ & 10489.8 & 56.7 & 1705 & 0.367 \\
\hline Chord member of $Y$ direction & $\phi 180 \times \mathrm{t} 21$ & 10489.8 & 56.7 & 1400 & 0.305 \\
\hline \multirow[t]{2}{*}{ Web member } & $\phi 150 \times \mathrm{t} 12$ & 5202.5 & 49.0 & 1162 & 0.240 \\
\hline & Bolt (mm) & $\begin{array}{c}\text { Sectional } \\
\text { area }\left(\mathrm{mm}^{2}\right)\end{array}$ & $\begin{array}{c}\text { Member } \\
\text { length }(\mathrm{mm})\end{array}$ & $\begin{array}{c}\text { Minimum } \\
\text { elongation (\%) }\end{array}$ & $\begin{array}{l}\text { Yield axial } \\
\text { force }(\mathrm{kN})\end{array}$ \\
\hline Chord member of $X$ direction & $\phi 30.0$ & 706.9 & 200 & 16 & 452.3 \\
\hline Chord member of $Y$ direction & $\phi 30.0$ & 706.9 & 200 & 16 & 452.3 \\
\hline \multirow[t]{3}{*}{ Web member } & $\phi 15.0$ & 254.5 & 267 & 16 & 162.9 \\
\hline & \multicolumn{5}{|c|}{ Wall depth: $0.4 \mathrm{~m}$} \\
\hline & Strut $(\mathrm{mm})$ & $\begin{array}{c}\text { Sectional } \\
\text { area }\left(\mathrm{mm}^{2}\right)\end{array}$ & $\begin{array}{l}\text { Cross-sectional } \\
\text { secondary } \\
\text { radius }(\mathrm{mm}) \\
\end{array}$ & $\begin{array}{c}\text { Member } \\
\text { length }(\mathrm{mm})\end{array}$ & $\begin{array}{c}\text { Slenderness } \\
\text { ratio/limit } \\
\text { slenderness ratio }\end{array}$ \\
\hline Chord member of $X$ direction & $\phi 180 \times \mathrm{t} 21$ & 10189.8 & 56.7 & 1705 & 0.367 \\
\hline Chord member of $Y$ direction & $\phi 180 \times \mathrm{t} 21$ & 10189.8 & 56.7 & 1400 & 0.305 \\
\hline \multirow[t]{2}{*}{ Web member } & $\phi 150 \times \mathrm{t} 12$ & 5202.5 & 49.0 & 994 & 0.240 \\
\hline & Bolt (mm) & $\begin{array}{c}\text { Sectional } \\
\text { area }\left(\mathrm{mm}^{2}\right)\end{array}$ & $\begin{array}{c}\text { Member } \\
\text { length }(\mathrm{mm})\end{array}$ & $\begin{array}{c}\text { Minimum } \\
\text { elongation (\%) }\end{array}$ & $\begin{array}{l}\text { Yield axial } \\
\text { orce }(\mathrm{kN})\end{array}$ \\
\hline Chord member of $X$ direction & $\phi 30.0$ & 706.9 & 200 & 16 & 452.3 \\
\hline Chord member of $Y$ direction & $\phi 30.0$ & 706.9 & 200 & 16 & 452.3 \\
\hline Web member & $\phi 15.0$ & 254.5 & 228 & 16 & 162.9 \\
\hline
\end{tabular}

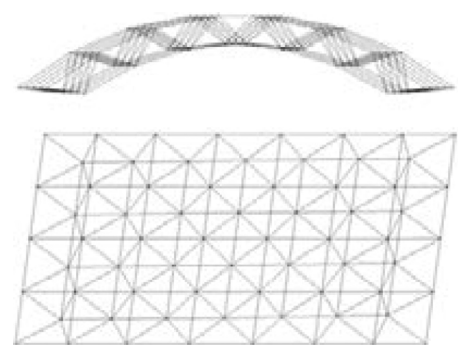

(a1) First mode $T_{1}=0.234 \mathrm{~s}$

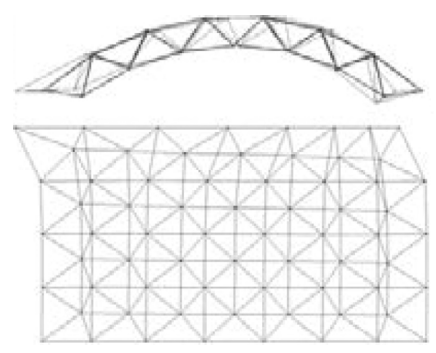

(a2) Third mode $T_{3}=0.050 \mathrm{~s}$

(a)

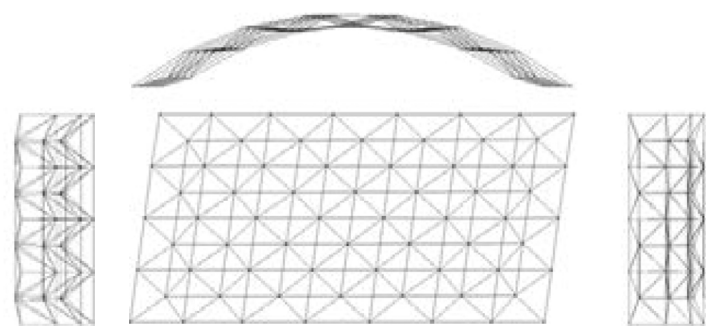

(b1) First mode $T_{1}=0.185 \mathrm{~s}$
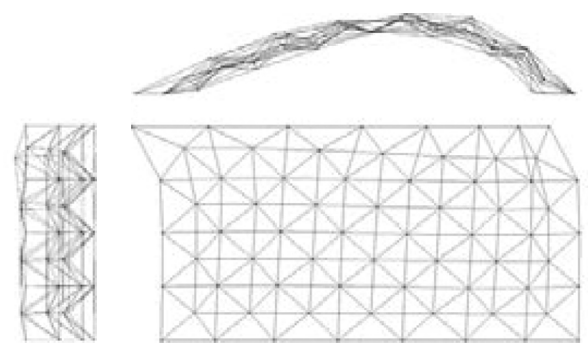

(b2) Third mode $T_{3}=0.049 \mathrm{~s}$

(b)

Figure 11: The first and third vibration modes and natural periods. (a) Wall depth: $1.0 \mathrm{~m}$. (b) Wall depth: $0.4 \mathrm{~m}$.

that the control of the dynamic collapse mechanism such as the steel bolt elongation can avoid a brittle collapse mechanism such as a chain of member buckling. Effect of the member buckling and yield elongation of the steel bolt on the seismic response out of the plane is also shown in comparison with the response of the wall structure subjected to the horizontal earthquake motions.

The evaluation method is also proposed by means of the limit displacement considering a ductility factor of the steel bolt within 2.0. This means that the response control can be 


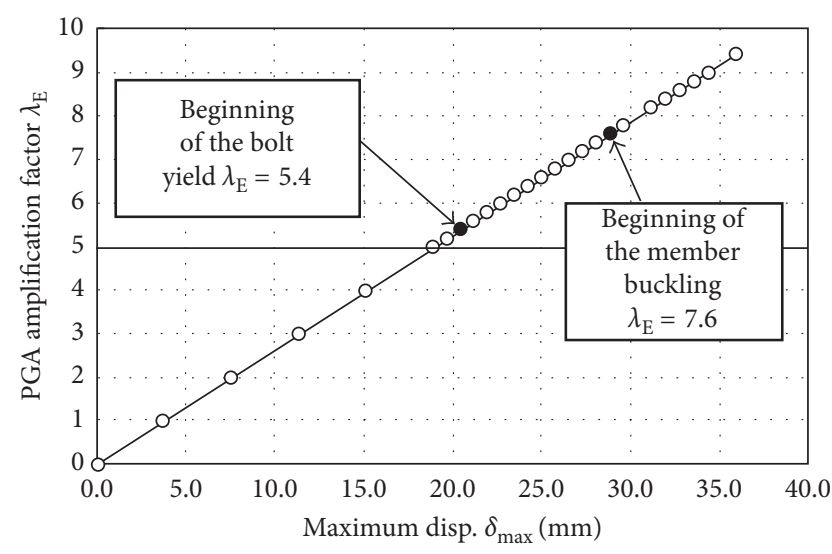

Figure 12: $\lambda_{\mathrm{E}}$ and $\delta_{\max }$ of the wall depth with $1 \mathrm{~m}$.

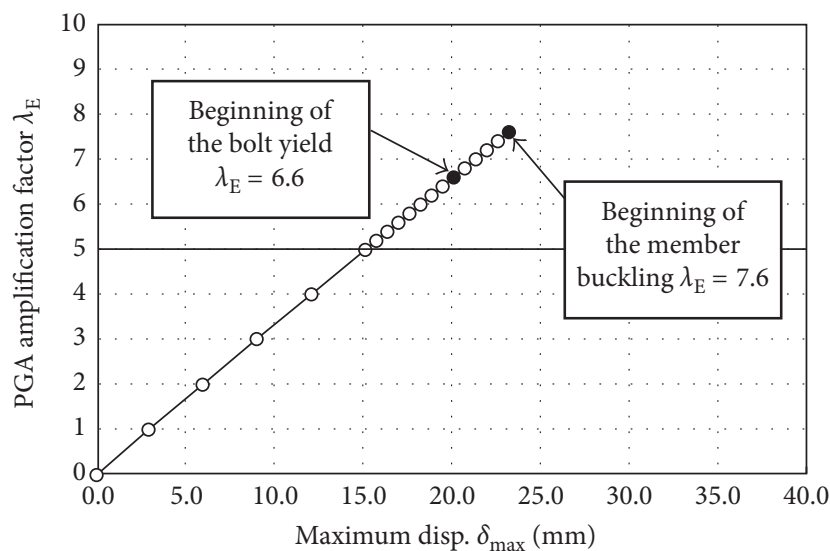

Figure 13: $\lambda_{\mathrm{E}}$ and $\delta_{\max }$ of the wall depth with $0.4 \mathrm{~m}$.

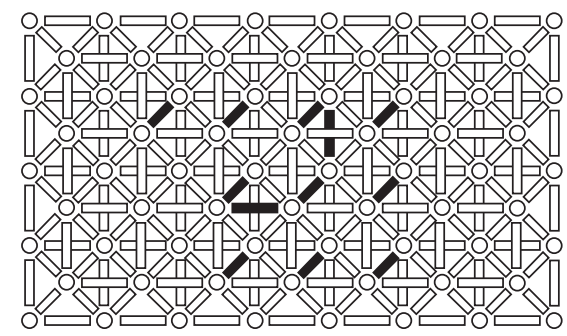

(a)

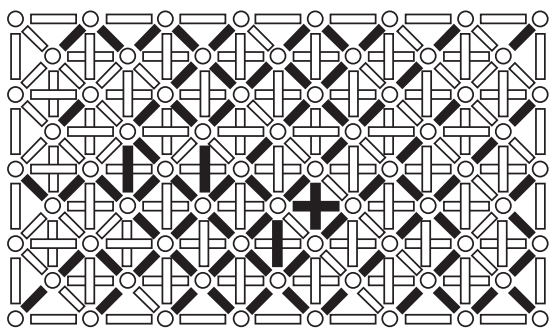

(b)

Figure 14: Continued.

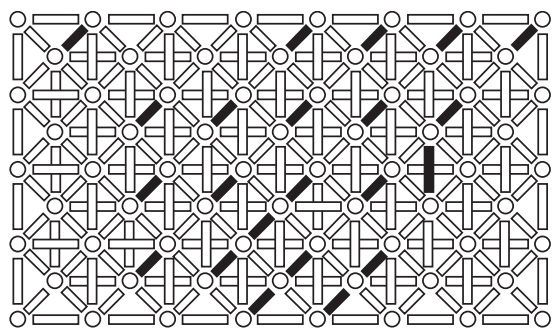

(c)

Figure 14: Location of the bolt yield of the wall depth with $1 \mathrm{~m}$ and $0.4 \mathrm{~m}$. (a) Case of $\lambda_{\mathrm{E}}=7.4$ (1 m depth). (b) Case of $\lambda_{\mathrm{E}}=9.4(1 \mathrm{~m}$ depth). (c) Case of $\lambda_{\mathrm{E}}=7.6$ (0.4 $\mathrm{m}$ depth).

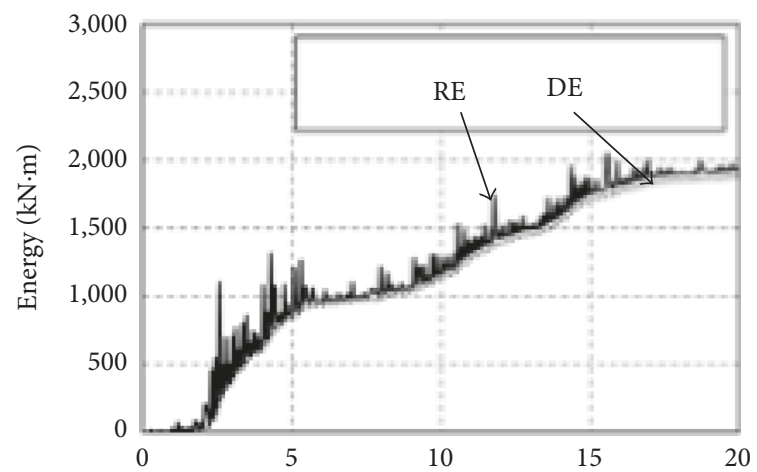

(a)

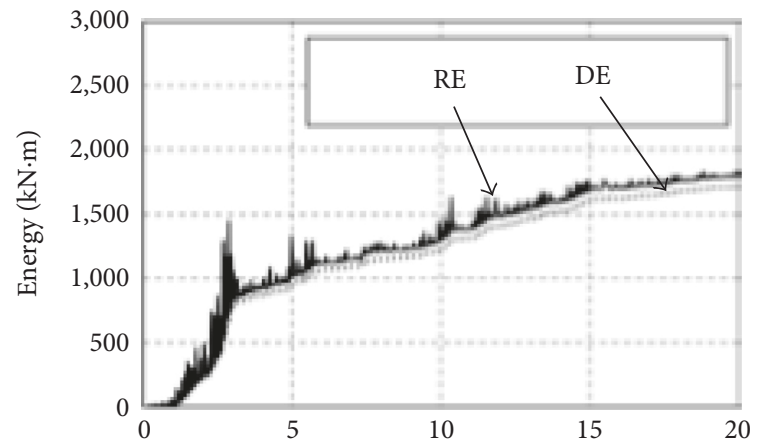

(b)

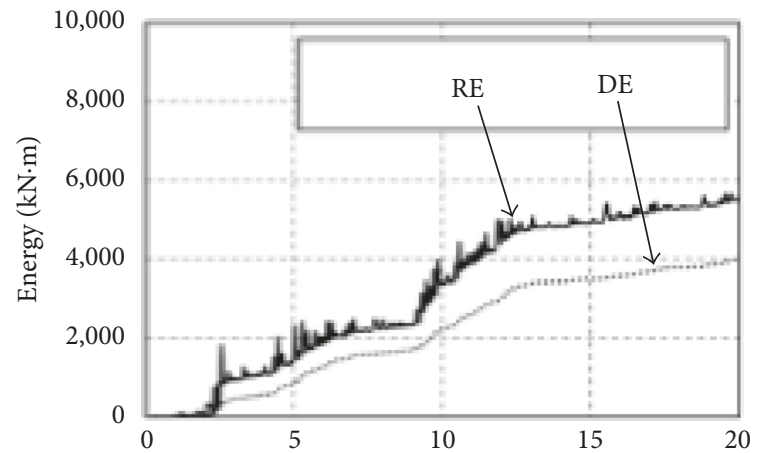

(c)

FIGURE 15: Time-history energy response of the restoring force of the member and the damping of the structure to the in-plane $(X)$ direction component. (a) $1 \mathrm{~m}$ wall depth $\left(\lambda_{\mathrm{E}}=7.4\right)$. (b) $0.4 \mathrm{~m}$ wall depth $\left(\lambda_{E}=7.6\right)$. (c) $1 \mathrm{~m}$ wall depth $\left(\lambda_{E}=9.4\right)$. $\mathrm{RE}=$ restoring force energy; $\mathrm{DE}=$ damping energy. 


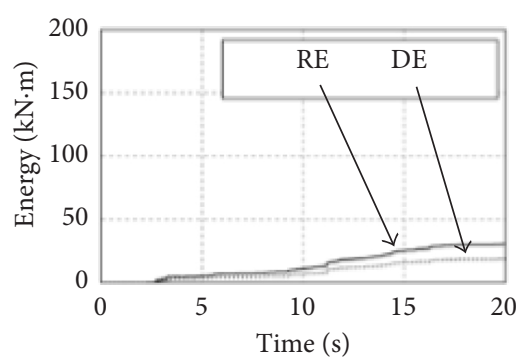

(a)

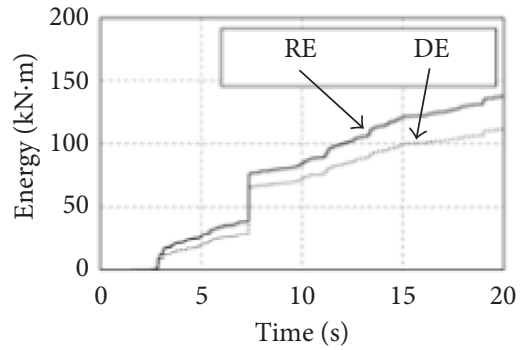

(b)

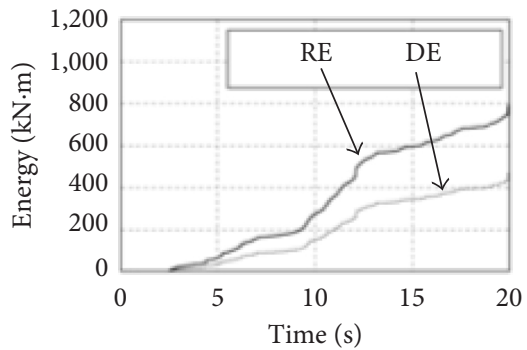

(c)

Figure 16: Time-history energy response to the out-of-plane $(Z)$ direction component. (a) $1 \mathrm{~m}$ wall depth $\left(\lambda_{\mathrm{E}}=7.4\right)$. (b) $0.4 \mathrm{~m}$ wall depth $\left(\lambda_{\mathrm{E}}=7.6\right)$. (c) $1 \mathrm{~m}$ wall depth $\left(\lambda_{\mathrm{E}}=9.4\right) . \mathrm{RE}=$ restoring force energy; $\mathrm{DE}=$ damping energy.

TABLE 2: Ratio of the total energy in the out-of-plane $(Z)$ direction to that in the in-plane $(X)$ direction.

\begin{tabular}{lccccc}
\hline Failure type & Wall depth $(\mathrm{m})$ & $\lambda_{\mathrm{E}}$ & $\begin{array}{c}\text { Consumption energy in the in-plane } \\
\text { direction } E_{\mathrm{i}}(\mathrm{kN} \cdot \mathrm{m})\end{array}$ & $\begin{array}{c}\text { Consumption energy in the out-of-plane } \\
\text { direction } E_{\mathrm{o}}(\mathrm{kN} \cdot \mathrm{m})\end{array}$ & $\begin{array}{c}E_{\mathrm{o}} /\left(E_{\mathrm{i}}+E_{\mathrm{o}}\right) \\
(\%)\end{array}$ \\
\hline \multirow{2}{*}{ Steel bolt yield } & 1.0 & 7.4 & 1937.8 & 137.33 & 1.54 \\
& 0.4 & 7.6 & 1814.7 & 790.69 & 7.06 \\
\hline $\begin{array}{l}\text { Member } \\
\text { buckling }\end{array}$ & 1.0 & 9.4 & 5588.6 & 72.39 \\
\hline
\end{tabular}

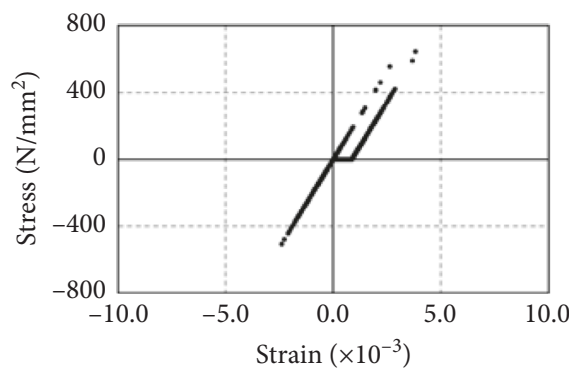

(a)

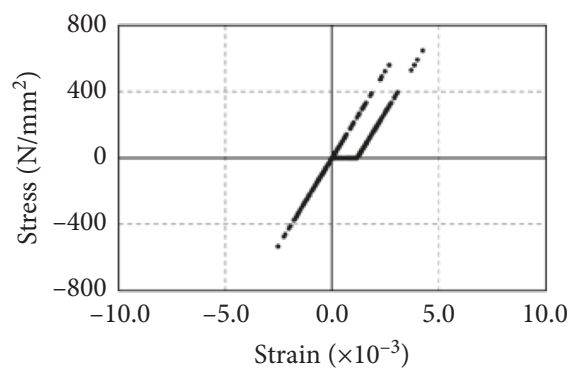

(b)

Figure 17: Relationship between stress and strain of the web member. (a) $1 \mathrm{~m}$ wall depth before the member buckling $\left(\lambda_{\mathrm{E}}=7.4\right)$. (b) $0.4 \mathrm{~m}$ wall depth before the collapse $\left(\lambda_{\mathrm{E}}=7.6\right)$.

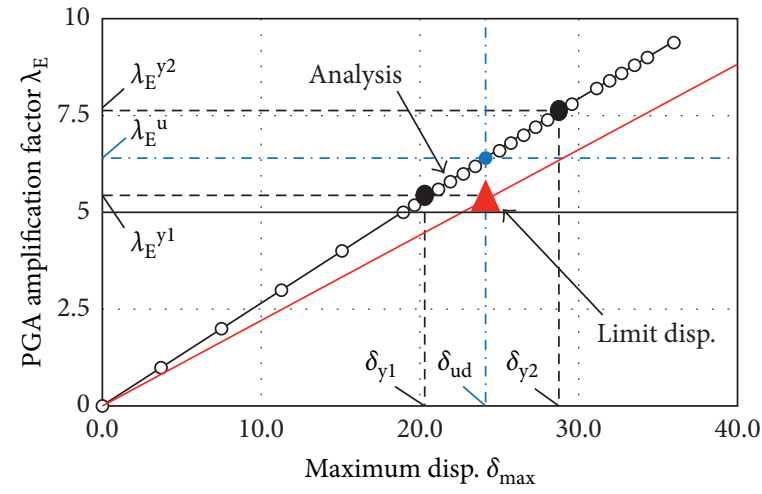

(a)

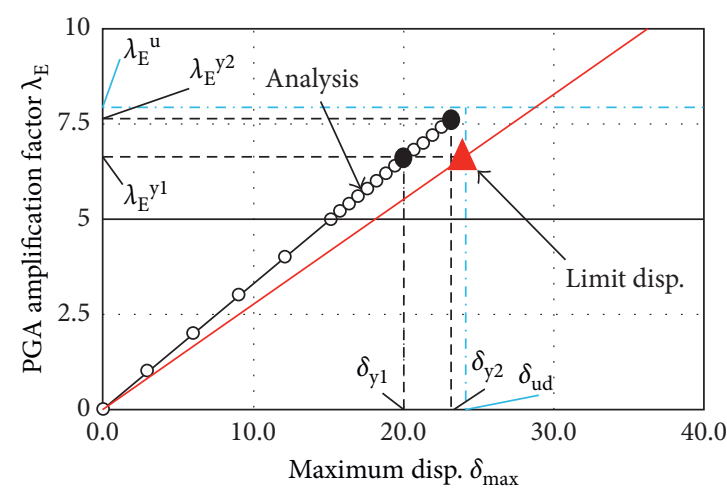

(b)

FIgURE 18: Comparison between the limit displacement and the analysis. (a) $1 \mathrm{~m}$ wall depth. (b) $0.4 \mathrm{~m}$ wall depth. 
feasible by the damper connection such as the steel bolt elongation due to tension stress.

\section{Data Availability}

The data used to support the findings of this study are available from the corresponding author upon request.

\section{Conflicts of Interest}

The author declares that there are no conflicts of interest.

\section{Acknowledgments}

This work was supported by JSPS KAKENHI (Grant no. 18K04427).

\section{References}

[1] K. Ishikawa, S. Okubo, Y. Hiyama, and S. Kato, "Evaluation method for predicting dynamic collapse of double layer latticed space truss structures due to earthquake motion," International Journal of Space Structures, vol. 15, no. 3, pp. 249-257, 2000.

[2] S. Okubo, Y. Hiyama, K. Ishikawa, R. Wendel, and L. Fischer, "Load capacity and plastic deformable ability of aluminum alloy double layer latticed wall subjected to plane load," in Proceedings of the IASS Symposium, Nagoya, Japan, 2001.

[3] K. Ishikawa and S. Kato, "Elastic-plastic buckling analysis of reticular dome subjected to earthquake motion," International Journal of Space Structures, vol. 12, no. 3-4, pp. 205-215, 1997.

[4] Y. Taniguchi, P. L. Gould, and M. Kurano, "Earthquake input energy at dynamic collapse for double-layer cylindrical lattice roofs," Journal of the International Association for Shell and Spatial Structures, vol. 49, no. 2, 2008.

[5] F. Fan, S. Z. Shen, and G. A. R. Parke, "Theoretical and experimental study of vibration reduction in braced domes using a viscous damper system," International Journal of Space Structures, vol. 19, no. 4, pp. 195-202, 2004.

[6] M. Midorikawa, "Performance-based seismic design provisions for buildings in Japan," in Proceedings of the IASS 2005, vol. 1, pp. 307-316, Bucharest, Romania, September 2005.

[7] G. C. Giuliani, "Overview on the dynamic control of structures," in Proceedings of the IASS, 2002, pp. 561-567, Warsaw, Poland, 2002.

[8] Z. P. Zeng, "Structural analysis and design of the latticed shell for Fujian Gymnasium," Journal of Spatial Structures, vol. 13, no. 2, pp. 44-48, 2007.

[9] L. Ilzarbe, M. J. Álvarez, E. Viles, and M. Tanco, "Practical applications of design of experiments in the field of engineering: a bibliographical review," Quality and Reliability Engineering International, vol. 24, no. 4, pp. 417-428, 2008.

[10] European Committee for Standardization (CEN), Eurocode 8: Design of Structures for Earthquake Resistance Part 1: General Rules, Seismic Actions and Rules for Buildings (EN 1998-1: 2004), European Committee for Standardization (CEN), Brussel, Belgium, 2004.

[11] FEMA-356, NEHRP Guidelines for the Seismic Rehabilitation of Buildings, Building Seismic Safety Council, FEMA, Washington, DC, USA, 2000.
[12] H. G. Park, T. Eom, and H. Lee, "Factored modal combination for evaluation of earthquake load profiles," Journal of Structural Engineering, vol. 133, no. 7, pp. 956-968, 2007.

[13] S. K. Kunnath, "Identification of modal combinations for nonlinear static analysis of building structures," ComputerAided Civil and Infrastructure Engineering, vol. 19, no. 4, pp. 246-259, 2004.

[14] R. K. Goel and A. K. Chopra, "Extension of modal pushover analysis to compute member forces," Earthquake Spectra, vol. 21, no. 1, pp. 125-139, 2005.

[15] J. C. Reyes and A. K. Chopra, "Three dimensional modal pushover analysis of buildings subjected to two components of ground motion, including its evaluation for tall buildings," Earthquake Engineering and Structural Dynamics, vol. 40, no. 7, pp. 789-806, 2011.

[16] A. K. Chopra and R. K. Goel, "A modal pushover analysis procedure for estimating seismic demands for buildings," Earthquake Engineering and Structural Dynamics, vol. 31, no. 3, pp. 561-582, 2002.

[17] G. Gupta and S. K. Kunnath, "Adaptive spectra-based pushover procedure for seismic evaluation of structures," Earthquake Spectra, vol. 16, no. 2, pp. 367-392, 2000.

[18] C. Casarotti and R. Pinho, "An adaptive capacity spectrum method for assessment of bridges subjected to earthquake action," Bulletin of Earthquake Engineering, vol. 5, no. 3, pp. 377-390, 2007. 


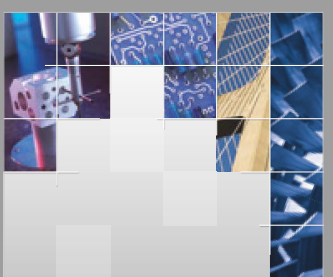

\section{Enfincering}
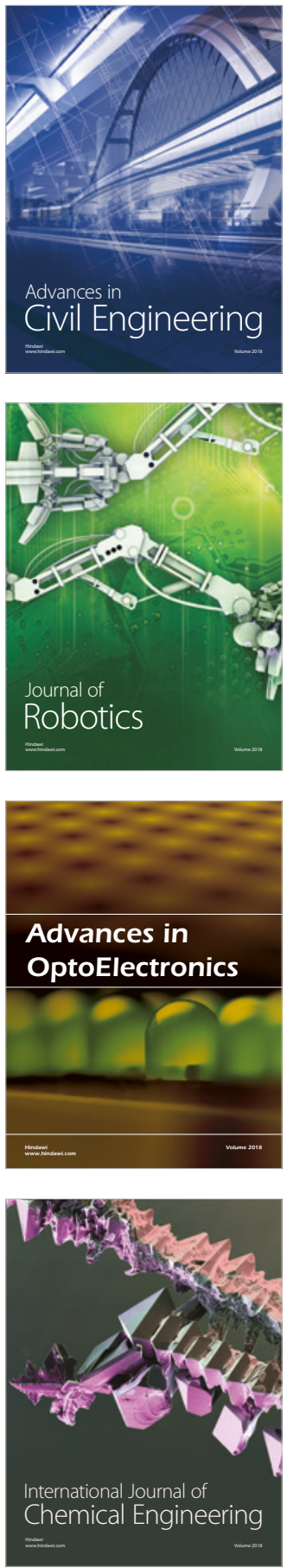

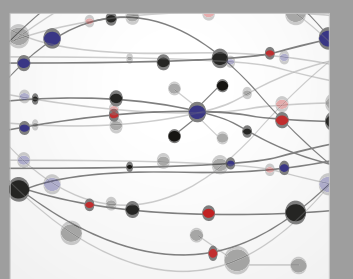

\section{Rotating \\ Machinery}

The Scientific World Journal

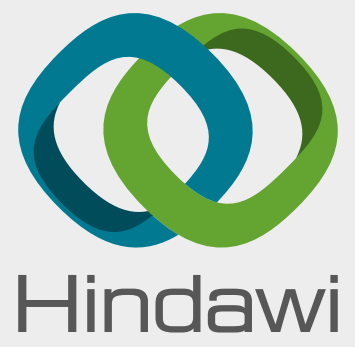

Submit your manuscripts at

www.hindawi.com
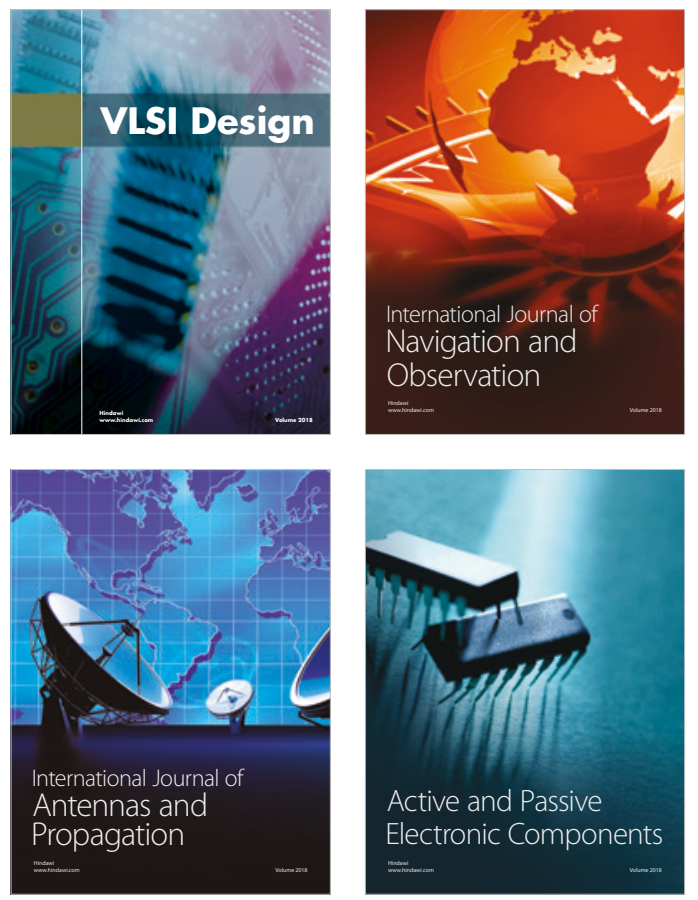
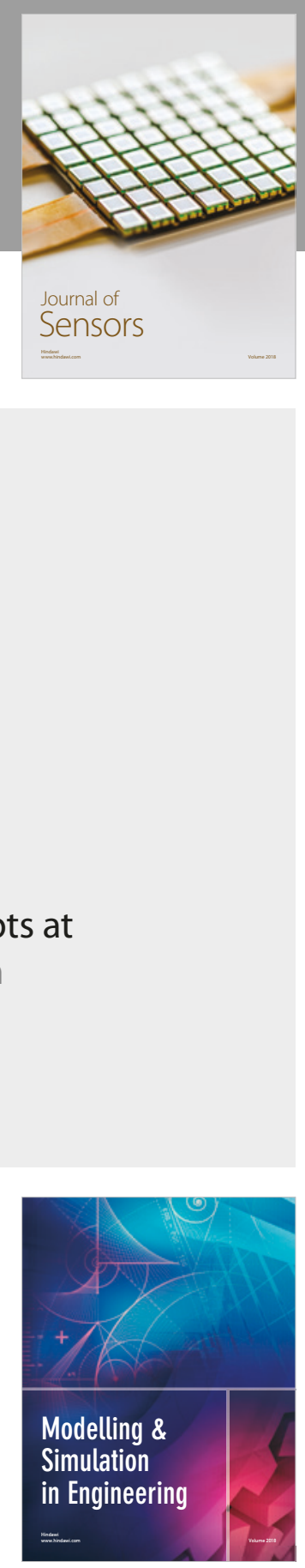

\section{Advances \\ Multimedia}
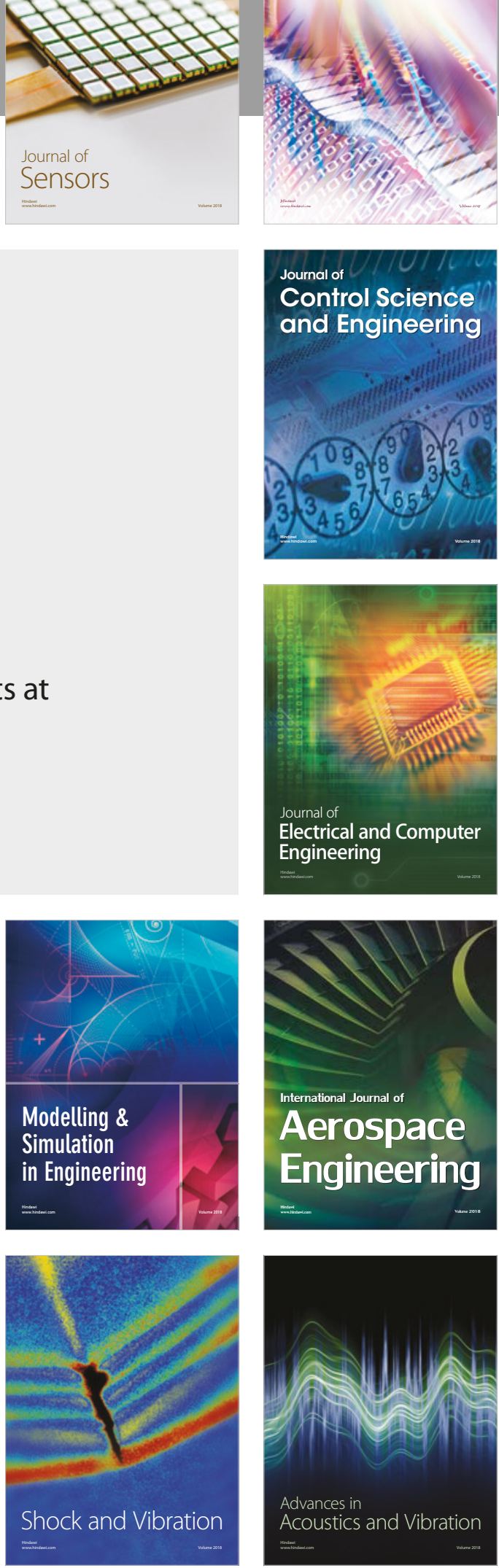